\title{
Research on the Construction of Study Style in University
}

\author{
Shasha Zhu \\ China West Normal University \\ Nanchong Sichuan, PRC \\ Correspondence: Zhu Shasha \\ School of Foreign Languages, China West Normal University, \\ No. 1 Shi Da Road, Nanchong, 637009,Sichuan, China
}

Keywords: Colleges and universities; Construction of study style; Measures

\begin{abstract}
The study style is the concentrated reflection of university spirit, the request of essential higher education goal, and the footstone of the university construction and development. The construction of study style is closely related to the adult success of college students, and it is the key to the success of the university. This paper will discuss the concrete measures for the construction of study style from five aspects: First, concerning about supervision: raising students' consciousness and transforming learning motivation into concrete actions; Second, healthy promotion: ensuring efficiency and eliminating the students' mental disorders and difficulties; Third, cultural auxiliary: enhance students' quality by integrating the major into activities to promote the students' all-round success; Fourth, setting a good example: Show and turn the students' learning goals into excellent examples; Fifth, the improvement of postgraduate enrolment rate: helping students to detail and extend their goals to get a promotion.
\end{abstract}

\section{Introduction}

The construction of study style is the critical goal of high school education, as well as an important guarantee of the quality of the university. More importantly, it also determines the quality of the students. Strengthening the construction of study style can promote the formation of good style of study, provide the fundamental guarantee for the sustainable development of colleges and universities, create a good learning environment for students' development and cultivate the students' interest to form autonomous learning motives. It is not only representing the level of student management, but also the ability of running the university. In a word, the construction of study style should be the lifeline and the priority of educational work in colleges and universities. Thus, based on the practice experience of construction of study style in university, I conclude five measures about the construction of study style as follows:

\section{Concerning about Supervision: Raising Students' Consciousness and Transforming Learning Motivation into concrete Actions}

The cultivation of good study style requires teachers, especially university counselors and head teachers, to care about students, education and supervisor. Colleges and universities should not only cultivate students' ideas of independent development, but should also try to be "meticulous and comprehensive".

Development and Guidance of Study Planning: The counselor and head teacher instruct each student to formulate the term study goal and plan, check the implementation of the plan regularly, and urge the students to complete the study plan and achieve the learning goal.

Supervision of the Self-study: The counselor and head teacher are responsible for the supervision and inspection of the freshmen and sophomores for reading on morning and studying in evening from every Mondays to Fridays. 
Supervision of the Classroom Learning: The university teacher counts the students to the class carefully in each class, provides feedback to head teacher in time, educates and manages students together. The counselor and head teacher practice the lecture system, complete the lecture notes and summarize the students' classroom learning.

Supervision of Apartment Study: The counselor and head teacher visit the dormitory not regularly, concerned and learn about life in the student apartment, discover problems in time and guide students to study hard.

Strict Examination of the Exam Period: Each class holds a class meeting to study the school examination irregularities treatment method conscientiously and strengthen the good faith education; the counselor and head teacher cooperate with the supervisor to test the discipline strictly, carry out serious education to the cheating students, and give corresponding punishment.

From life to study and finally having examination, from dormitory to classroom and eventually stepping into society, the university should attach great importance to the guidance, raising students' consciousness and transforming learning motivation into concrete actions.

\section{Healthy Promotion: Ensuring Efficiency and Eliminating the Students' Mental Disorders and Difficulties}

The physical and mental quality of contemporary university students not only affects their own development, but also relates to the cultivation of the new talents of the Chinese nation, which is related to the rise of the Chinese nation. Meanwhile, physical and mental health is the foundation of students' learning. Therefore, the construction of study style in university should pay attention to the cultivation of students' physical and mental health. Organize a series of activities, promote the students to strengthen physical exercise, and cultivate students' healthy psychology

Organization of Morning Running Activities: "Good health makes good study". We can organize freshmen and sophomores to carry out morning running exercises. By keeping exercising, we can improve their physical quality and ensure that students have full energy to study.

Development of Weekly Sports Activities: Organize students to carry out 1-2 hours of class sports every week, promote students' physical and mental health, strengthen class cohesion, and lay a solid foundation for creating good academic atmosphere.

Guidance of Psychology: The school's party and government leaders, university counselors and head teachers form the study psychological counseling group, and regular class meetings will be held for group study counseling; For individual problem students, "one-to-one" counseling and development of counseling can help alleviate the learning pressure, solve the learning confusion, adjust the state of mind, and study easily.

Organization of a Series of Mental Health Activities: In combination with the school's characteristics, we will hold a series of mental health activities, and do a good job in the students' mental health, ensure the formation of a good academic atmosphere.

Physical health and mental health is a prerequisite for the normal study and life of a university student. The school attaches great importance to the health of students in colleges and universities, eliminates the students' psychological obstacles and difficulties in a timely manner, so students can keep for a long time energy and hearty spirit and make it play personal potential in study and life to achieve and develop individual.

\section{Cultural Auxiliary: Enhance Students' Quality by Integrating the Major into Activities to Promote the Students' All-round Success}

In order to flourish the campus culture, improve students' comprehensive quality and innovative spirit, edify sentiment, enlighten wisdom, and promote the all-round development of students, the college should carry out a series of characteristic student activities in combination with the specialty of the college (taking the School of foreign languages for instance) 
Hold a Series of High Level Academic Lectures. Let the students listen to the master, interact with the master to promote the students' foreign language using level and cultural quality and improve the further development of the college foreign language education career.

Hold a Sino-foreign Cultural Exchange Festival. By comparing the differences between Chinese and foreign cultures, we can help students understand Chinese and foreign cultures more deeply and broadly.

Hold Series of Activities with the Characteristics of Profession. So as to improve students' professional level and language skills, we can hold some special activities such as the speech contest, the foreign language writing competition, language poetry reading competition, foreign language translation, etc.

On the whole, rich and colorful cultural activities are the carrier of campus culture, good culture carrier to form a healthy campus cultural atmosphere, can edify sentiment, enlighten students mind, enhance the students' quality, promote the all-round development of students.

\section{Setting a Good Example: Show and Turn the Students' Learning Goals into Excellent Examples}

"Role models are visible forces." An advanced model is a flag, a ruler. A good example is the power of action, the expression of a silent example. In order to build a good academic atmosphere, colleges and universities should carry out a series of activities, shaping the example, encouraging and stimulating the enthusiasm and motivation of students to learn.

Organize the Student Cadre Training Camp: Strengthen the construction of the student cadre team, controlling of the achievement level strictly, and implement the result of a veto system, we can ensure that the students who are good at both characteristics and study are the main student cadres, and then train them to be the student leader, and set up the correct orientation. Through the development of a lecture, an exchange of experience, a quality development, a practice and a series of activities, we can improve the quality of the student cadre, and build a cadre team of students who are hard, academic, and have complete well quality.

Hold Three-good Student Contests: school can hold "star of students" competitions to select students who do well, own strong ability as well as high quality. And then through the campus network media to broadcast their good deeds, by doing so, we can motivate good effect in other students and encourage them to learn from those examples.

The Model Dormitory Competition: hold the dormitory of demonstration appraisal activities, and the evaluation standards should include morning and evening self-study class attendance, grades level ranking, learning progress, research situation and awards recommendation, etc. and then encourage and commend those excellent students.

Hold the Public Lecture of Excellent University Graduates. Within the scope of the whole school, we can invite the provincial or college outstanding representatives to do reports, and through the campus network media to proclaim their good deeds, set in a powerful example to inspire students to study and work hard.

Hold the Optimal Exchanges of Excellent Construction and Competition. By holding exchange report of outstanding students' experience who performed well in entrepreneurship, innovation subject contests, we can encourage the students to take an active part in innovation entrepreneurship competition and various academic competitions.

Through setting up various examples to represent the talent standards, we should start from details, use the force of excellent students, and shorten the distance between ideal and reality. Let ordinary students feel those excellent people just beside them; let us create a positive study environment all together. 


\section{The Improvement of Postgraduate Enrolment Rate: Helping Students to Detail and Extend Their Goals to Get a Promotion}

Taking postgraduate entrance exams has become a goal of many contemporary university students, university students should pay attention to postgraduate examination work to improve the students postgraduate examination success rate and the level of guidance so as to helping students to realize postgraduate examination dream paving to take effective measures and carry out series of activities.

Deepen the Research Mobilization: In the first year of the university, we can hold the development trend of employment situation, life development plan and other education to guide students to "aim high and pursue excellence", and recognize the necessity and importance of the postgraduate entrance examination. In the sophomore year, we can hold postgraduate entrance examination mobilization about "dream is not far away", through the theme class meeting, the lecture, the campus media publicity and so on widely carry on the ideological mobilization to set up the examination goal. In the third year, we will carry out the mobilization work in the field of determination, specialty, planning and so on.

Practice the Tutorial System: Partial mobilization, led by party and government leaders, the university professional teachers constitute the team of postgraduate students. A teacher in charge of 10 students, give the fresh postgraduate examination students in "one to one" for guidance, check supervise postgraduate examination planning implementation regularly and help contact tutors, get ready for a second interview, admitted to regulate, etc.

Carry out the Special Training for the Postgraduate Entrance Examination: Invite experts and third party training institutions to focus on English, politics, professional courses, etc.

Hold the Postgraduate Entrance Examination and the Experience Exchange Meeting: Hold the conference and experience exchanging meeting to honor the students who get success in postgraduate exam and let them deliver the speech. By doing these, we can help students build confidence and work hard.

By active mobilization and phased, hierarchical effective guidance to the student, we can inspire the student with a strong and hard work will to detail and extend their goals. The integration of all parties' research resources and building the communication platform actively, help the students to further clarify the direction of efforts, and strengthen the confidence of the postgraduate entrance examination, which will greatly promote the formation of the excellent academic atmosphere of the university.

\section{Conclusion}

The construction of study style is the eternal theme of the talent cultivation in colleges and universities, which is the important criteria to carry out the party's education policy and the important symbol of the level of college education. Besides, the construction of study style is a key work for the institution of higher education maintains persistent effort and an important factor to test the college and universities whether can develop a new era of real moral talent. A good study style is the foundation and premise of students' growth. It is a powerful spiritual force that motivates students to work hard and strive for success, and it also worked as an important guarantee for improving the quality of education. Thus, the construction of study style in university should be emphasized and insisted forever.

\section{References}

[1] Chen Yudong. Study on the Construction of Study Style in Concept Subjective and Specialty [J]. Higher Education Exploration, 2014 (4) :92 to 96

[2] Zhao zhi. Study on the Construction of College Study Style: Current Situation, Reason and Countermeasures [J]. China Electric Power Education, 2010 (18) :178 to 180

[3] Zhang zhenbo. Strengthen the Countermeasures and Suggestions of Construction of the College Study Style [J]. Modern Vocational Education, 2017 (25) :163 
[4] Zhang mengmeng. The problems and Countermeasures of Construction of the Study Style in New Era [J]. Heilongjiang Education (Higher Education Research \& Appraisal), 2017 (3) :61 to 63

[5] Cheng guangguo. The Strategy of the Construction of the College Study Style [J]. Chinese \& Foreign Entrepreneurs, 2017 (2) :164 